\title{
OBTENCIÓN DE UN INÓCULO FÚNGICO PARA LA DEGRADACIÓN DE UN COLORANTE AZO POR FERMENTACIÓN EN ESTADO SÓLIDO
}

\section{OBTAINING A FUNGAL INOCULUM FOR DEGRADATION OF AN AZO DYE BY SOLID STATE FERMENTATION}

\author{
Ana Jaramillo ${ }^{1}$, Sara Jiménez ${ }^{2}$, Andrés Merino ${ }^{3}$, Angelina Hormaza ${ }^{4}$
}

\begin{abstract}
${ }^{1}$ Ing. Biológica. Maestría en Biotecnología. Investigadora Grupo SIRYTCOR. Facultad de Ciencias, Universidad Nacional de Colombia, Núcleo El Volador, Medellín, Antioquia-Colombia, e-mail: ancjaramilloma@unal.edu.co; ${ }^{2}$ Estudiante de Ingeniería Biológica. Investigadora Grupo SIRYTCOR. Facultad de Ciencias, Universidad Nacional de Colombia, Núcleo el Volador, Medellín, Antioquia-Colombia, e-mail: sjimenezc@unal.edu.co; ${ }^{3}$ Estudiante de Ingeniería Biológica. Investigador Grupo SIRYTCOR. Facultad de Ciencias, Universidad Nacional de Colombia, Núcleo El Volador, Medellín, Antioquia-Colombia, e-mail: ramerinor@unal.edu.co; ${ }^{4}$ Magister en Química Orgánica. Doctora en Ciencias Químicas. Directora del Grupo de Investigación SIRYTCOR. Docente Asociada Escuela de Química, Facultad de Ciencias, Universidad Nacional de Colombia, Núcleo El Volador, Medellín, Antioquia-Colombia, e-mail: ahormaza@unal.edu.co
\end{abstract}

Rev. U.D.C.A Act. \& Div. Cient. 17(2): 577-585, Julio-Diciembre, 2014

\section{RESUMEN}

La industria textil y alimentaria genera efluentes con grandes cantidades de colorantes tipo azo, ocasionando un deterioro general del ecosistema, debido a la disminución de los procesos fotosintéticos y del oxígeno disponible para la biota acuática. Para el tratamiento de dichos contaminantes, se destaca la adsorción de colorantes sobre un residuo agroindustrial, seguida de un proceso de degradación, bajo condiciones de Fermentación Estado Sólido (FES), con hongos de podredumbre blanca. El objetivo de esta investigación fue evaluar el inoculo fúngico obtenido de diferentes medios de cultivo y su efecto en el porcentaje degradación del colorante rojo 40, bajo condiciones de FES. Los diferentes medios de cultivo evaluados fueron un medio líquido de extracto de malta y los medios sólidos PDA (Potato Dextrose Agar) y salvado de trigo. Los ensayos fueron realizados utilizando las especies fúngicas Pleurotus ostreatus y Trametes versicolor; el proceso de degradación fue monitoreado durante 20 días y, posteriormente, fue determinado el porcentaje de degradación. Los mejores resultados de degradación fueron 93,19\%, para T. versicolor y, de $63,15 \%$, para $P$. ostreatus, los cuales, se alcanzaron con el inóculo fúngico obtenido del medio salvado de trigo y suplementado con extracto de malta. La variación en las condiciones de crecimiento del inóculo incidió, de forma significativa, en el porcentaje de degradación del colorante rojo 40.
Palabras clave: Fermentación en estado sólido, hongos de podredumbre blanca, inóculo, rojo 40, tuza de maíz.

\section{SUMMARY}

The textile and food industry generate effluents with large amounts of azo dyes, leading to a general detriment of the ecosystem due to the decrease of the photosynthetic process and the available oxygen to aquatic biota. The dyes adsorption over an agro-industrial waste, followed by a degradation process under Solid State Fermentation (SSF) conditions with white-rot fungi is highlighted for the treatment of those pollutants. The aim of this research was to evaluate the fungal inoculum obtained from different culture media and its effect on the degradation percentage of the red dye 40 under SSF conditions. Liquid malt extract medium and PDA solid medium and wheat bran were the different culture media evaluated. The assays were performed using the fungal species Pleurotus ostreatus and Trametes versicolor; the degradation process was monitored for 20 days and then the degradation percentage was determined. The best dye degradation percentage was $93.19 \%$ by $T$. versicolor and $63.15 \%$ by $P$. ostreatus, percentages reached with the obtained fungal inoculum from wheat bran medium and supplemented with malt extract. The variation in the conditions of inoculum growth had a significant incidence on the efficiency of the biodegradation process. 
Key words: Solid state fermentation, white rot fungi, inoculum, red 40, corn cob.

\section{INTRODUCCIÓN}

En la actualidad, la presencia de colorantes en cuerpos de agua es una problemática de creciente interés. Se estima que, aproximadamente, existen más de 100.000 colorantes disponibles en el comercio, la mayoría de los cuales, son difíciles de degradar, debido a su compleja estructura química (Zollinger, 2004). Es importante destacar que un sinnúmero de los tintes sintéticos utilizados en la industria son azo derivados (Forgacs et al. 2004). La implementación de colorantes sintéticos se ha incrementado en las industrias textiles, de alimentos y de teñido, debido a su facilidad y rentabilidad en la síntesis, firmeza, alta estabilidad a la luz, a la temperatura, a los detergentes, al ataque microbiano y la variedad en color que brindan, comparada con los colorantes naturales (Neill et al. 1999). La presencia de colorantes en el agua, menores de $1 \mathrm{mgL}^{-1}$, es altamente visible y afecta la cualidad estética, su transparencia y la solubilidad del oxígeno en lagos, ríos y otros cuerpos de agua (Moawad et al. 2003)as a short-term screening test for environmental impact assessment. The eight-textile dyes and Eithidium bromide dye (as positive control; además, reduce la penetración de luz, dificultando el proceso fotosintético (Walsh et al. 1980). El rojo 40 (R40) es un colorante sintético tipo azo, de amplia utilización en la industria textil, debido a su eficiencia en los procesos de tinción y bajo costo. Asimismo, es empleado en confitería y subproductos de la industria cárnica (Soylak et al. 2011). Estudios han reportado que es recalcitrante y tóxico a concentraciones de más del 10\% de la dieta (Vorhees, 1983; Anonymous, 1984) y podría causar cáncer de colon en ratones (Shimada et al. 2010). Debido a esto es importante implementar tratamientos efectivos, para la eliminación de este tipo de colorantes.

Dentro de las técnicas de biorremediación, el método de adsorción ha ganado aceptación en los últimos años, debido a su probada eficiencia en la remoción de colorantes disueltos, en comparación con las metodologías de tratamiento convencionales (Robinson et al. 2001a). De igual forma, un gran número de investigaciones han reportado elevados porcentajes de remoción de colorantes usando residuos agroindustriales, convirtiéndolos en adsorbentes alternativos y de bajo costo, para el tratamiento de efluentes coloreados (Ramakrishna \& Viraraghavan, 1997; Kumar et al. 2003); entre ellos, cabe señalar que la tuza de maíz (TM) es un residuo agrícola de amplia disponibilidad en Colombia y de comprobada capacidad adsorbente, que ha permitido la remoción eficiente de colorantes, de naturaleza tanto aniónica como catiónica (Grande \& Orozco, 2013; Robinson et al. 2002). Es valioso señalar que la optimización del proceso de adsorción del colorante R40 sobre TM ya ha sido reportado (Moreno et al. 2012).

En el proceso de adsorción se logra transferir el contaminante desde el medio acuoso hasta el residuo agrícola. Por tanto, si se requiere un procedimiento integral para la biorremediación de colorantes, se debe buscar una metodología complementaria que degrade dicho contaminante impregnado sobre el residuo. Diversos procesos biológicos se han implementado para la degradación de colorantes (Banat et al. 1996; Pearce, 2003), entre ellos, cabe resaltar, el uso de hongos de podredumbre blanca (Wesenberg, 2003; Levin et al. 2004).

Los hongos de podredumbre blanca (HPB) son organismos eficientes en la degradación de la lignina, un polímero estructural de las plantas leñosas. Este proceso está asociado con la producción de enzimas peroxidasas y fenoloxidasas, como lignina peroxidasa (LiP), manganeso peroxidasa (MnP) y lacasa, las cuales, son sintetizadas extracelularmente y poseen la capacidad de escindir una gran variedad de enlaces moleculares heterogéneos (Robinson \& Nigam, 2008; Zhuo et al. 2011). Con base en lo anterior, varios autores han planteado que si dichos organismos pueden degradar compuestos de estructura compleja, también pueden ejercer acción hidrolítica sobre compuestos xenobióticos y recalcitrantes de estructura más simple, como los hidrocarburos aromáticos policíclicos y colorantes sintéticos (Erkurt et al. 2007; Borchert \& Libra, 2001).

La FES es una estrategia altamente eficiente para el crecimiento de los HPB y la producción de las enzimas mencionadas, para la degradación de colorantes (Pandey, 2001; Krishna, 2005). Se caracteriza por el crecimiento del microorganismo sobre un sustrato sólido en ausencia de agua libre (Pandey, 2003). Esta metodología fue seleccionada en el presente estudio para la degradación del colorante R40 impregnado en la TM, aprovechando el alto contenido de lignina, de celulosa y de hemicelulosa, presentes en el residuo (Moreno et al. 2012), que lo constituyen como un sustrato adecuado para recrear el ambiente natural de estos organismos y potenciar la producción de las enzimas ligninolíticas (Nigam et al. 2000; Boer et al. 2004).

Existen diversos factores que influyen en la eficiencia del proceso de FES, tales como: $\mathrm{pH}$, temperatura, humedad, microorganismo, concentración de colorante adsorbido en el soporte, naturaleza del sustrato y tamaño de partícula, entre otras (Prabhakar et al. 2005; Membrillo et al. 2008). Estudios recientes han demostrado que otra variable relevante es la composición del medio donde crece el microorganismo, ya sea en medio líquido o en sólido (Bhagnagar et al. 2006; Norsalwani et al. 2012). Se han utilizado diversas formas de inoculación en la FES para la degradación de colorantes, entre ellas se destacan, agregados celulares, en forma de 
pellets homogenizados (Nigam et al. 2000); inóculo líquido con alta densidad celular (Zeng et al. 2011); esporas (Selvam et al. 2003) y discos sólidos de agar, removidos de la zona de crecimiento exponencial (Koyani et al. 2013).

Paralelamente, múltiples estudios han señalado que la exposición gradual del inóculo a concentraciones crecientes de colorante permite adaptar el cultivo microbiano a las condiciones posteriores de fermentación y, de esta forma, incrementar su rendimiento (Swamy \& Ramsay, 1999; Rani et al. 2009). Otro factor importante es la adición de una fuente de carbono y de energía al inicio del proceso, ya que su disponibilidad está directamente relacionada con el crecimiento del microorganismo y con la producción de enzimas ligninolíticas (Koyani et al. 2013; Stajić et al. 2006). Al respecto, estrategias como fijar la proporción carbono:nitrógeno y la adición de inductores, de vitaminas y de sales, entre otras, han sido implementadas para potenciar la degradación de colorantes (Membrillo et al. 2008; Levin et al. 2010).

En este contexto, el objetivo del presente trabajo fue evaluar el inóculo fúngico obtenido de diferentes medios y su efecto en el porcentaje de degradación del colorante R40 adsorbido en TM, mediante FES. Se evaluaron diez tipos de ensayos de FES, usando las especies fúngicas $T$. versicolor y $P$. ostreatus, las cuales, han reportado porcentajes de degradación del orden de 87\% (Dhillon et al. 2012; Membrillo et al. 2008). En los ensayos, se modificó la composición del medio de crecimiento para la obtención del inóculo, la presencia o ausencia de colorante en el medio, el tipo de inóculo para la FES y la adición de extracto de malta al inicio de la fermentación. Posteriormente, se compararon los ensayos considerando, como parámetro, el porcentaje de degradación del colorante y, finalmente, se aplicó una prueba de ANOVA simple, para determinar sus diferencias estadísticas.

\section{MATERIALES Y MÉTODOS}

Adsorción del R40: El residuo agrícola TM fue obtenido en un mercado local y sometido a un proceso de pretratamiento, que incluyó lavado, molienda y tamizado. Dicho pretratamiento y el proceso de adsorción, se llevaron a cabo de acuerdo con Moreno et al. (2012). Se preparó un litro de solución de colorante, con una concentración de $43,98 \mathrm{gL}^{-1}$, que se mantuvo en contacto con $10 \mathrm{~g}$ de $\mathrm{TM}$, en un Erlenmeyer de 1,0L con agitación continua de 150rpm, a $25^{\circ} \mathrm{C}$, durante dos horas. Terminado el tiempo de contacto, el adsorbente fue separado de la solución mediante filtración y la absorbancia del colorante no adsorbido fue medida en un espectrofotómetro Perkin Elmer UV-Vis Lambda 35, a la longitud de onda de máxima absorción $\lambda_{\operatorname{máx}}=502 \mathrm{~nm}$, para determinar la concentración de colorante retenido en la TM. El porcentaje de remoción del colorante (\%R), se calcula mediante la ecuación 1 , donde $\mathrm{C}_{0}$ y $\mathrm{C}_{\mathrm{f}}$ son las concentraciones del R40 inicial y final, respectivamente.

$$
\% R=\frac{C_{0}-C_{f}}{C_{0}} \times 100
$$

Microorganismos y condiciones de conservación: Los HPB, $T$. versicolor y $P$. ostreatus, fueron obtenidos del Laboratorio de Cultivo de Tejidos Vegetales de la Universidad de Antioquia y cultivados en agar PDA (Potato Dextrose Agar), a $4^{\circ} \mathrm{C}$, siendo subcultivados cada 30 días, en el mismo medio.

Preparación de inóculos: Se prepararon dos medios líquidos y cuatro medios sólidos para usarlos como inóculo en el proceso de degradación del colorante por FES. El primer medio (M1) contiene extracto de malta $20 \mathrm{gL}^{-1}$ y, el segundo (M2), extracto de malta $20 \mathrm{gL}^{-1}$ y R40 $10 \mathrm{mgL}^{-1}$. Las soluciones fueron preparadas con agua destilada estéril, en una cabina de flujo Streamline SCV-4A2. A $40 \mathrm{~mL}$ de cada medio, se agregaron cuatro círculos de micelio fresco del respectivo hongo cultivado en agar PDA, tomados de la zona de crecimiento exponencial. Posteriormente, los medios fueron incubados a $28^{\circ} \mathrm{C}$ y sometidos a una agitación de 120rpm, en un shaker Heidolph Unimax 1010 Inkubator 1000, durante cinco días.

El tercer medio (M3) incluye extracto de malta $20 \mathrm{gL}^{-1}$ y agaragar $15 \mathrm{gL}^{-1}$; el cuarto medio (M4) contiene $10 \mathrm{mgL}^{-1}$ de R40 y la misma composición de M3; el quinto (M5) incluye glucosa $10 \mathrm{gL}^{-1}$, peptona $5 \mathrm{gL}^{-1}$, extracto de levadura $2 \mathrm{gL}^{-1}, \mathrm{KH}_{2} \mathrm{PO}_{4}$ $0,1 \mathrm{gL}^{-1}, \mathrm{MgSO}_{4} 7 \mathrm{H}_{2} \mathrm{O} \quad 0,05 \mathrm{gL}^{-1}, \mathrm{MnSO}_{4} . \mathrm{H}_{2} \mathrm{O} \quad 0,076 \mathrm{gL}^{-1}$, extracto de salvado de trigo y agar-agar $15 \mathrm{gL}^{-1}$ (Ha et al. 2001) y, el sexto medio (M6) contiene $10 \mathrm{mgL}^{-1}$ de R40 y la misma composición de M5. Estos medios fueron preparados con agua destilada, autoclavados, vertidos en cajas de Petri, en una cabina de flujo Streamline SCV-4A2 e inoculados con dos círculos de micelio fresco $(\mathrm{d}=10 \mathrm{~mm})$, tomados de la zona de crecimiento exponencial del respectivo hongo obtenido de agar PDA. Las cajas de Petri, se llevaron a incubar a $28^{\circ} \mathrm{C}$, durante cinco días.

Fermentación en Estado Sólido FES: Para cada hongo, se ejecutaron diez ensayos diferentes, cada uno con tres réplicas, según el tipo de inóculo usado y la adición o no adición de extracto de malta $0,2 \mathrm{gL}$ a la TM coloreada, lo cual, condujo a un total de 60 ensayos. La fermentación, se llevó a cabo en Erlenmeyers de $50 \mathrm{~mL}$, con $500 \mathrm{mg}$ de tuza teñida, proporción carbono:nitrógeno de 40:1, humedad del $80 \%$ y temperatura de $25^{\circ} \mathrm{C}$, durante 20 días.

El análisis bromatológico de la TM, realizado en el Laboratorio de Análisis Químico y Bromatológico de la Universidad Nacional de Colombia - Sede Medellín, mostró una 
composición de 57,13\%, fibra en detergente ácido; 85,34\%, fibra en detergente neutro; 7,39\%, lignina y, 0,6\%, nitrógeno. Según estos valores y la cantidad de colorante retenido en la tuza, se determinó que la proporción carbono:nitrógeno de tuza teñida es de 67,84 , asumiendo que el $16 \%$ de la proteína es nitrógeno y que el $40 \%$ de los carbohidratos son carbono (Membrillo et al. 2008), por tanto, para ajustar la proporción carbono:nitrógeno, se utilizó una solución de nutrientes, que contiene $0,0156 \mathrm{mgL}^{-1}$, de extracto de levadura y $80 \mathrm{mgL}^{-1}$, de $\mathrm{CuSO}_{4} .5 \mathrm{H}_{2} \mathrm{O}$, como inductor de la producción de enzimas ligninolíticas (Robinson et al. 2001b). Según ensayos previos efectuados en el grupo de investigación, para alcanzar una humedad del $80 \%$ para TM, se deben añadir $2,4 \mathrm{~mL}$ de agua por cada gramo del residuo agrícola; por consiguiente, se adicionaron $1,0 \mathrm{~mL}$ de solución de nutrientes y $0,2 \mathrm{~mL}$ ya sea de agua, de inóculo líquido o de solución de extracto de malta $\left(8 \mathrm{gL}^{-1}\right)$, según el ensayo correspondiente, cuyas características se detallan en la tabla 1.

Desorción: Una vez concluida la fermentación para remover el colorante residual impregnado en la TM y determinar el porcentaje de biodegradación, a cada Erlenmeyer se le adicionaron $34 \mathrm{~mL}$ de una solución de $\mathrm{KOH}$, de concentración $0,01 \mathrm{molL}^{-1}$ y se sometió a una agitación de 140rpm, durante dos horas, en un shaker Heidolph Unimax 2010; estas condiciones fueron optimizadas en estudios anteriores del grupo de investigación. Transcurrido el tiempo de agitación, los residuos de micelio y TM fueron separados de la solución, utilizando una centrifuga Hettich EBA20, durante diez minutos, a 5500rpm. La concentración en el sobrenadante del R40 corresponde a la cantidad desorbida $\left(C_{d}\right)$ y fue medida mediante espectofotometría UV-Vis, como se describe en el apartado de adsorción del R40.

El proceso de desorción alcanzó a remover alta cantidad del colorante impregnado en la tuza, la cual, se calculó mediante la ecuación 2 , donde $\mathrm{C}_{\mathrm{a}}$ es la concentración de colorante adsorbido en la tuza y $\mathrm{C}_{\mathrm{d}}$ es la concentración desorbida; sin embargo, existe cierta cantidad que no alcanza a ser desorbida, por lo tanto, se requiere determinar el colorante total no de degradado, $\mathrm{Ct}$, que representa el total de colorante, tanto retenido en el soporte como el disuelto después del tiempo de fermentación (ecuación 3). Finalmente, el porcentaje de colorante degradado por el HPB (\%D), se determina con la ecuación 4.

$$
\begin{aligned}
\% d & =\frac{C_{d}}{C_{a}} \times 100 \\
C_{t} & =\frac{100}{\% d} \times C_{d} \\
\% D & =\frac{C_{a}-C_{t}}{C_{a}} \times
\end{aligned}
$$

ANOVA Simple: Como herramienta estadística, se utilizó un ANOVA simple, para determinar diferencias estadísticas entre las medias. En particular, las Pruebas de Rangos Múltiples brindan información sobre las medias que son significativamente diferentes de otras. El número de observaciones para cada corrida fue de 30 , correspondientes a los diez ensayos con sus tres réplicas. Este análisis, se llevó a cabo para las dos especies de hongos evaluadas con el software Statgraphics Centurion XV.II versión 16.1.18. Licencia, edición de evaluación gratuita.

\section{RESULTADOS Y DISCUSIÓN}

Adsorción del R40 sobre TMy su desorción: Transcurrido el tiempo de contacto, la concentración final, $\mathrm{C}_{\mathrm{f}}$, de la solución de R40 usada para la adsorción por TM fue $1,59 \mathrm{mgL}^{-1}$, con un porcentaje de remoción de 96,38\%. La desorción del colorante desde TM mostró un porcentaje de desorción de $82,46 \%$, para ambas especies.

Fermentación en Estado Sólido: El porcentaje de degradación, \%D, obtenido en cada uno de los diez ensayos para las cepas $T$. versicolor y $P$. ostreatus, se presenta en la

Tabla 1. Características de los ensayos llevados a cabo por FES, tanto para T. versicolor como para $P$. ostreatus.

\begin{tabular}{|c|c|c|}
\hline Ensayos & $0,2 \mathrm{~mL}$ de medio líquido & Extracto de malta $(\mathrm{mL})$ \\
\hline E1 & $M 1$ & - \\
\hline E2 & $M 2$ & - \\
\hline \multicolumn{2}{|c|}{ Dos discos agar $(\mathrm{d}=10 \mathrm{~mm})$} \\
\hline E3 & $M 3$ & - \\
\hline E4 & $M 3$ & 0,2 \\
\hline E5 & $M 4$ & - \\
\hline E6 & $M 4$ & 0,2 \\
\hline E7 & $M 5$ & - \\
\hline E8 & $M 5$ & 0,2 \\
\hline E9 & $M 6$ & - \\
\hline E10 & $M 6$ & 0,2 \\
\hline
\end{tabular}


tabla 2. En ella, se especifican los subgrupos obtenidos en la prueba de múltiples rangos, aquellos con letras diferentes mostraron diferencias estadísticamente significativas, con un nivel del 95,0\% de confianza. Se identificaron diez grupos homogéneos, para T. versicolor y nueve, para P. ostreatus.

FES con T. versicolor: Los ensayos 1 y 2, con inóculos obtenidos de cultivos sumergidos, presentaron menores porcentajes de degradación, lo que indica que el medio líquido afecta el crecimiento del hongo, particularmente, debido a la formación de agregados celulares que, una vez inoculados sobre el soporte sólido, requieren mayor tiempo de adaptación durante la fermentación. También se debe tener en cuenta que el medio líquido no fue suplementado con otros nutrientes, como sales, lo cual, influye en el desarrollo del hongo. Cabe señalar que Jain et al. (2013) reporta que algunos hongos filamentosos cultivados en medio líquido forman agregados celulares, impidiendo su desarrollo natural en forma miceliar, que facilita la producción de metabolitos secundarios, como las enzimas ligninolíticas. Igualmente, dichos agregados pueden reducir la concentración de células activas en el volumen inoculado. Este tipo de inóculo fue considerado en el presente estudio, dado que otros autores han reportado porcentajes de degradación de colorantes entre 80 y $90 \%$, usando como inóculo HPB, cultivados en medio líquido (Zeng et al. 2011).

De forma general, para los ensayos del 3 al 10, en los que el hongo fue inoculado al medio sólido directamente en su forma miceliar, se observó un incremento en la eficiencia del proceso. En particular, para los ensayos del 7 al 10, E7-E10, donde el inóculo proviene del medio salvado de trigo, se alcanzaron mayores porcentajes de degradación, comparados con los obtenidos en los ensayos E3-E6, cuyo inóculo procedió del medio extracto de malta. Estos resultados destacan la importancia que tiene el tipo de fuente de carbono y la presencia de componentes, como peptona, extracto de levadura y demás sales, en el medio de donde se obtiene el inóculo, para potenciar la producción de enzimas ligninolíticas de los HPB, importantes en la degradación de colorantes. En los ensayos del 3 al 6 , no se observó un patrón que evidencie el efecto, positivo o negativo, de la adición, ya sea de colorante al inóculo o del extracto de malta a la fermentación. Estos resultados, se pueden explicar, debido a la baja reproducibilidad que presentan los procesos biológicos y a la ausencia de nutrientes complementarios en el medio extracto de malta, que influyeron en la variación del comportamiento del hongo.

Por otro lado, al comparar los ensayos E7 con E9 y E8 con E10, se observó que el mayor porcentaje de degradación corresponde a aquellos ensayos que carecen de colorante en el medio del inóculo. En contraste con los resultados del presente estudio, algunos autores reportaron que exponer el microorganismo al compuesto a degradar en etapas previas a la fermentación, puede mejorar el rendimiento de dicho proceso (Swamy \& Ramsay, 1999; Kumar et al. 2009). Los resultados obtenidos de este trabajo, se pueden argumentar teniendo en cuenta que la presencia del colorante acelera la producción de enzimas ligninolíticas. Así, durante los días de incubación del inóculo, el metabolismo secundario del hongo, se pudo haber activado y, por tanto, al momento de ser inoculado en la FES, el microorganismo no se encontraba en su fase de crecimiento exponencial y al llegar a un nuevo medio sólido necesitó un proceso de adaptación, que redujo su capacidad proliferativa.

Tabla 2. Porcentajes de degradación del colorante R40 por FES con T. versicolor y P. ostreatus.

\begin{tabular}{|c|c|c|c|}
\hline Ensayos & $\begin{array}{c}\text { Degradación (\%D) } \\
\text { T. versicolor }\end{array}$ & Ensayos & $\begin{array}{c}\text { Degradación (\%D) } \\
\text { P. ostreatus }\end{array}$ \\
\hline E1a & 6,44 & E1a & 8,58 \\
\hline E2b & 4,70 & E2b & 6,97 \\
\hline E3c & 39,94 & E3c & 20,28 \\
\hline E4d & 31,36 & E4d & 13,55 \\
\hline E5e & 26,16 & E5e & 11,53 \\
\hline E6f & 49,52 & E6e & 10,82 \\
\hline E7g & 89,82 & E7f & 41,97 \\
\hline E8h & 93,19 & E8g & 50,11 \\
\hline E9i & 54,96 & E9h & 46,00 \\
\hline E10j & 63,58 & E10i & 63,15 \\
\hline
\end{tabular}


Al comparar los ensayos E7 con E8 y E9 con E10, se evidenció que a los ensayos, a los cuales se agregó extracto de malta al inicio de la fermentación, presentaron mayores porcentajes de degradación. Estos resultados coinciden con los de Koyani et al. (2013), quienes reportan mayor producción de enzimas que degradan lignina, en presencia de una fuente de carbono, disponible e inmediata, para el hongo. En conclusión, el mayor porcentaje de degradación de 93,19\% del colorante R40 para T. versicolor fue con un inóculo obtenido del medio M5 (Tabla 1) y con la adición de extracto de malta E8 (Tabla 2).

Análisis de regresión simple: El análisis estadístico mostró que los ensayos presentaron diferencias estadísticas entre sí, lo cual, confirma la validez de las variaciones efectuadas en los medios utilizados para obtener los inóculos. En la figura 1a, se muestra la media de las réplicas del \%D para cada uno de los ensayos de T. versicolor. También, se muestra un intervalo alrededor de cada media basado en el procedimiento de la diferencia mínima significativa de Fisher, LSD. Ésta establece que si dos medias son iguales, sus intervalos se traslaparán un $95 \%$ de las veces. Cualquier par de intervalos que no se traslapen verticalmente corresponden a pares de medias, que tienen una diferencia estadísticamente significativa.

FES con $P$. ostreatus: Al igual que para $T$. versicolor, en $P$. ostreatus los ensayos 1 y 2 presentaron los menores porcentajes de degradación. En los ensayos del 3 al 6, se observó que la adición de extracto de malta no tuvo un efecto apreciable, ya que E4 presentó menor \%D respecto a E3. Por su parte, E5 y E6 no son estadísticamente diferentes. En este mismo grupo de ensayos, se apreció que aquellos inóculos obtenidos de un medio que contenía colorante no potenciaron la degradación durante la FES, similar a lo observado con T. versicolor.

Para los ensayos del inóculo proveniente de salvado de trigo, E7-E10, se observó la tendencia encontrada con T. versicolor, presentando mayores porcentajes de degradación, que aquellos ensayos cuyo inóculo se obtuvo del medio extracto de malta,
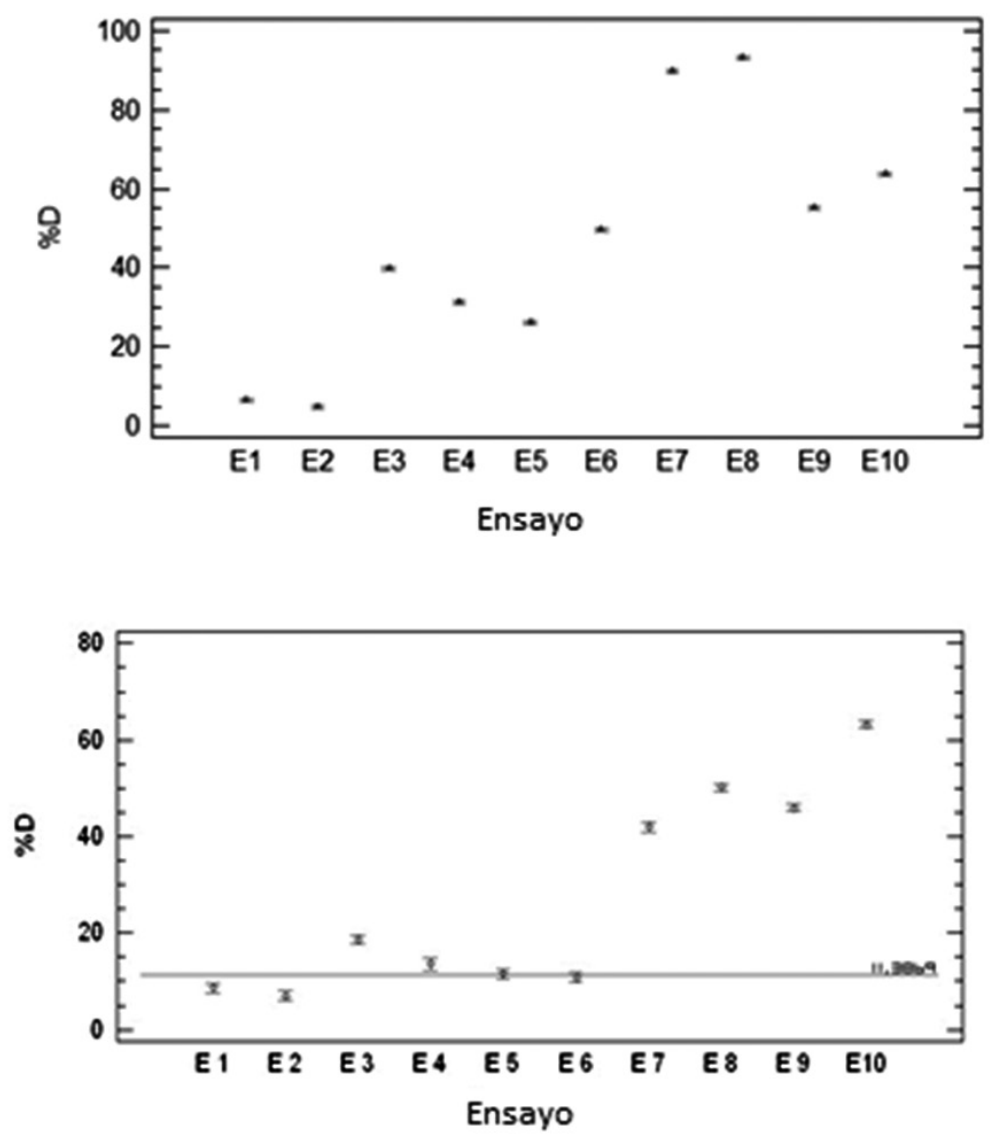

Figura 1. Diferencia mínima significativa de Fisher de los ensayos de degradación de R40 por FES. a) Especie fúngica T. versicolor y b) Especie fúngica $P$. ostreatus. 
E3-E6, reiterando la importancia de la elección de la fuente de carbono, en la que crece el inóculo. En este caso, la adición de extracto de malta y la presencia de colorante registra un efecto positivo en el porcentaje de degradación del R40. El efecto de la presencia de colorante en el medio de donde se obtiene el inóculo, difiere del hallado para la especie T. versicolor, mostrando las diferencias de crecimiento, de adaptación y de desarrollo metabólico, entre las especies de HPB. El mayor porcentaje de degradación del colorante R40 con $P$. ostreatus fue de $63,15 \%$, con un inóculo obtenido del medio M6 (Tabla 1) y con la adición de extracto de malta E10 (Tabla 2).

Análisis de regresión simple: En la figura $1 \mathrm{~b}$, se muestra la media de las réplicas del \%D para cada uno de los ensayos con $P$. ostreatus. Además, se observa el intervalo alrededor de cada media, basado en el procedimiento de la diferencia mínima significativa de Fisher, LSD. La línea punteada resalta aquellos ensayos que no presentaron diferencia estadística y que corresponde a E5 y E6.

En conclusión, el mayor \%D del colorante R40, bajo condiciones de FES, fue obtenido con la especie T. versicolor, inoculada desde un medio sólido de salvado de trigo sin colorante y con extracto de malta al inicio de la fermentación, con un porcentaje de degradación del 93,19\%, mientras que con $P$. ostreatus, se alcanzó una degradación del colorante del $63,15 \%$, con el inóculo cultivado en medio salvado de trigo suplementado con R40 y con extracto de malta al inicio de la fermentación.

La composición del medio donde crece el inóculo es altamente influyente para la degradación del R40 por FES. Para las dos especies, los medios suplementados con salvado de trigo proporcionaron porcentajes de degradación entre 40 y $90 \%$, en tanto que aquellos constituidos por extracto de malta sólo registraron degradaciones entre 10 y $50 \%$, aproximadamente. La degradación del colorante R40 por FES con la especie T. versicolor, se vio potenciada con la adición de extracto de malta al inicio del proceso fermentativo. Sin fuente de carbono, se obtuvo una degradación de $89,82 \%$, mientras que con fuente de carbono, un porcentaje de 93,19\%.

El análisis estadístico permitió confirmar que la mayoría de los ensayos presentaron diferencias estadísticas, resaltando la importancia de la variación de las condiciones de crecimiento del inóculo usado en la FES, para la degradación de R40.

Agradecimientos: Los autores expresan agradecimientos a la Universidad Nacional de Colombia-Sede Medellín, por el apoyo a través de la infraestructura del Laboratorio de Química Experimental. Financiación: Este estudio fue financiado por el Programa Nacional de Semilleros de Investigación, Creación e Innovación de la Universidad Nacional de Colombia, proyecto Código 18551. Conflicto de intereses:
El manuscrito fue preparado y revisado con la participación de todos los autores, quienes declaramos que no existe conflicto de intereses, que ponga en riesgo la validez de los resultados presentados.

\section{BIBLIOGRAFÍA}

1. ANONYMOUS. 1984. Allura Red-Developmental and psychotoxic effects. Food Chem. Toxicol. 22:913-928.

2. BANAT, I.M.; NIGAM, P.; SINGH, D.; MARCHANT, R. 1996. Microbial decolorization of textile-dye- containing effluents : A review. Bioresour. Technol. 58:217227.

3. BHAGNAGAR, T.; RODRIGUEZ, J.A.; MATEOS, J.C.; NUNGARAY, J.; GONZA, V.; ROUSSOS, S.; CORDOVA, J. 2006. Improving lipase production by nutrient source modification using Rhizopus homothallicus cultured in solid state fermentation. Process. Biochem. 41:2264-2269.

4. BOER, C.G.; OBICI, L.; DE SOUZA, C.G.M.; PERALTA, R.M. 2004. Decolorization of synthetic dyes by solid state cultures of Lentinula (Lentinus) edodes producing manganese peroxidase as the main ligninolytic enzyme. Bioresour. Technol. 94(2):107-12.

5. BORCHERT, M.; LIBRA, J.A. 2001. Decolorization of reactive dyes by the white rot fungus Trametes versicolor in sequencing batch reactors. Biotechnol. Bioeng. 75(3):313-21.

6. DHILLON, G.S.; KAUR, S.; BRAR, S.K. 2012. In-vitro decolorization of recalcitrant dyes through an ecofriendly approach using laccase from Trametes versicolor grown on brewer's spent grain. Int. Biodeterior. Biodegrad. 72 (1): 67-75.

7. ERKURT, E.A.; ÜNYAYAR, A.; KUMBUR, H. 2007. Decolorization of synthetic dyes by white rot fungi, involving laccase enzyme in the process. Process Biochem. 42(10):1429-1435.

8. FORGACS, E.; CSERHÁTI, T.; OROS, G. 2004. Removal of synthetic dyes from wastewaters: a review. Environment. Int. 30(7):953-971.

9. GRANDE, D.; OROZCO, S. 2013. Producción y procesamiento del maíz en Colombia. Revista Científica Guillermo de Ockham. 11(1):97-110.

10. HA, H.C.; HONDA, Y.; WATANABE, T.; KUWAHARA, M. 2001. Production of manganese peroxidase by pel- 
let culture of the lignin-degrading basidiomycete, Pleurotus ostreatus. Appl. Microbiol. Biotechnol. 55(6):704-711.

11. JAIN, A.; MORLOK, C.K.; HENSON, J.M. 2013. Comparison of solid-state and submerged-state fermentation for the bioprocessing of switchgrass to ethanol and acetate by Clostridium phytofermentans. Appl. Microbiol. Biotechnol. 97(2):905-917.

12. KOYANI, R.D.; SANGHVI, G.V.; SHARMA, R.K.; RAJPUT, K.S. 2013. Contribution of lignin degrading enzymes in decolourisation and degradation of reactive textile dyes. Int Biodeter Biodegr. 77:1-9.

13. KRISHNA, C. 2005. Solid-state fermentation systems-an overview. Crit. Rev. Biotechnol. 25(1-2):1-30.

14. KUMAR, D.; JAIN, V.K.; SHANKER, G.; SRIVASTAVA, A. 2003. Utilisation of fruits waste for citric acid production by solid state fermentation. Process Biochem. 38(12):1725-1729.

15. KUMAR, K.; DASTIDAR, M.G.; SREEKRISHNAN, T.R. 2009. Effect of Process Parameters on Aerobic Decolourization of Reactive Azo Dye using Mixed Culture. Eng. Technol. 34:962-965.

16. LEVIN, L.; PAPINUTTI, L.; FORCHIASSIN, F. 2004. Evaluation of Argentinean white rot fungi for their ability to produce lignin-modifying enzymes and decolorize industrial dyes. Bioresour. Technol. 94(2):169-176.

17. LEVIN, L.; MELIGNANI, E.; RAMOS, A.M. 2010. Effect of nitrogen sources and vitamins on ligninolytic enzyme production by some white-rot fungi. Dye decolorization by selected culture filtrates. Bioresour. Technol. 101(12):4554-4563.

18. MEMBRILLO, I.; SÁNCHEZ, C.; MENESES, M.; FAVELA, E.; LOERA, O. 2008. Effect of substrate particle size and additional nitrogen source on production of lignocellulolytic enzymes by Pleurotus ostreatus strains. Bioresour. Technol. 99(16):7842-7847.

19. MOAWAD, H.; EL-RAHIM, W.M.A.; KHALAFALLAH, M. 2003. Evaluation of biotoxicity of textile dyes using two bioassays. J. Basic Microbiol. 43(3):218-229.

20. MORENO, A.; FIGUEROA, D.; HORMAZA, A. 2012. Diseño estadístico para la remoción eficiente del colorante rojo 40 sobre tusa de maíz. Producción más Limpia. 7(2):9-19.
21. NEILL, C.O.; HAWKES, F.R.; HAWKES, D.L.; LOURENC, N.D. 1999. Review Colour in textile effluents sources, measurement, discharge consents and simulation: a review. J. Chem. Technol. Biotechnol. 74:1009-1018.

22. NIGAM, P.; ARMOUR, G.; BANAT, I.M.; SINGH, D.; MARCHANT, R. 2000. Physical removal of textile dyes from effluents and solid-state fermentation of dye-adsorbed agricultural residues. Bioresour. Technol. 72:219-226.

23. NORSALWANI, T.; LAH, T.; NORULAINI, N.; AB, N.; HASNAN, N.J.; BEN, M.M. 2012. Cellulase activity in solid state fermentation of palm kernel cake with. Malays J. Microbiol. 8(4):235-241.

24. PANDEY, A. 2001. Solid State Fermentation in Biotechnology: Fundamentals and Applications. Neuropsychological rehabilitation. Asiatech Publishers Inc (New Delhi). 82:73-77.

25. PANDEY, A. 2003. Solid-state fermentation. Biochem. Eng. J. 13:81-84.

26. PEARCE, C. 2003. The removal of colour from textile wastewater using whole bacterial cells: a review. Dyes and Pigments. 58(3):179-196.

27. PRABHAKAR, A.; KRISHNAIAH, K.; JANAUN, J.; BONO, A. 2005. An overview of engineering aspects of solid state fermentation. Malays J. Microbiol. 1(2):10-16.

28. RAMAKRISHNA, K.; VIRARAGHAVAN, T. 1997. Dye removal using low cost adsorbents. Water Sci. Technol. 36(2-3):189-196.

29. RANI, R.; KUMAR, A.; SOCCOL, C.R.; PANDEY, A. 2009. Recent advances in solid-state fermentation. Biochem. Eng. J. 44:13-18.

30. ROBINSON, T.; CHANDRAN, B.; NIGAM, P. 2001 a. Studies on the production of enzymes by white-rot fungi for the decolourisation of textile dyes. Enzyme Microb. Technol. 29:575-579.

31. ROBINSON, T.; CHANDRAN, B.; NIGAM, P. 2002. Removal of dyes from an artificial textile dye effluent by two agricultural waste residues, corncob and barley husk. Environm.Int. 28(1-2):29-33.

32. ROBINSON, T.; SINGH, D.; NIGAM, P. 2001b. Solid-state fermentation: a promising microbial technology for 
secondary metabolite production. Appl. Microbiol. Biotechnol. 55(3):284-289.

33. ROBINSON, T.; NIGAM, P.S. 2008. Remediation of Textile Dye Waste Water Using a White-Rot Fungus Bjerkandera adusta Through Solid-state Fermentation (SSF). Appl. Biochem. Biotechnol. 151:618-628.

34. SELVAM, K.; SWAMINATHAN, K.; CHAE, K.S. 2003. Decolourization of azo dyes and a dye industry effluent by a white rot fungus Thelephora sp. Bioresour. Technol. 88(2):115-119.

35. SHIMADA, C.; KANO, K.; SASAKI, Y.F.; SATO, I.; TSUDA, S. 2010. Differential colon DNA damage induced by azo food additives between rats and mice. J. Toxicol. Sci. 35(4):547-554.

36. SOYLAK, M.; UNSAL, Y.E.; TUZEN, M. 2011. Spectrophotometric determination of trace levels of allura red in water samples after separation and preconcentration. Food Chem. Toxicol. 49(5):11831187.

37. STAJIĆ, M.; PERSKY, L.; FRIESEM, D.; HADAR, Y.; WASSER, S.P.; NEVO, E.; VUKOJEVIĆ, J. 2006. Effect of different carbon and nitrogen sources on laccase and peroxidases production by selected Pleurotus species. Enzyme Microb. Technol. 38(12):65-73.

38. SWAMY, J.; RAMSAY, J.A. 1999. Effects of glucose and $\mathrm{NH} 4$ concentrations on sequential dye decoloration by Trametes versicolor. Enzyme Microb. Technol. 25:278-284.
39. VORHEES, C.V. 1983. Developmental toxycity and psychotoxicity of FD and C Red dye No. 40 (Allura Red AC) in rats. Toxicol. 28(40):207-217.

40. WALSH, G.E.; BAHNER, L.H.; HORNING, W.B. 1980. Toxicity of textile mill effluents to freshwater and estuarine algae, crustaceans and fishes. Environ. Pollut. 21(388):169-179.

41. WESENBERG, D. 2003. White-rot fungi and their enzymes for the treatment of industrial dye effluents. Biotechnol. Adv. 22(1-2):161-187.

42. ZENG, X.; CAI, Y.; LIAO, X.; ZENG, X.; LI, W.; ZHANG, D. 2011. Decolorization of synthetic dyes by crude laccase from a newly isolated Trametes trogii strain cultivated on solid agro-industrial residue. J. Hazard. Mater. 187(1-3):517-525.

43. ZHUO, R.; MA, L.; FAN, F.; GONG, Y.; WAN, X.; JIANG, M.; ZHANG, X.; YANG, Y. 2011. Decolorization of different dyes by a newly isolated white-rot fungi strain Ganoderma sp.En3 and cloning and functional analysis of its laccase gene. J. Hazard. Mater. 192(2):855-73.

44. ZOLLINGER, H. 2004. Color Chemistry. Synthesis, Properties and Applications of Organic Dyes and Pigments. $3^{\text {rd }}$ revised edition. Angewandte Chemie. 43(40):5291-5291.

Recibido: Abril 8 de 2014

Aceptado: Septiembre 29 de 2014

Como citar:

Jaramillo, A.; Jiménez, S.; Merino, A.; Hormaza, A. 2014. Obtención de un inóculo fúngico para la degradación de un colorante azo por fermentación en estado sólido. Rev. U.D.C.A Act. \& Div. Cient. 17(2): 577-585. 